Open Access

\title{
Prediction of complications in a high-risk cohort of patients undergoing corrective arthrodesis of late stage Charcot deformity based on the PEDIS score
}

\author{
Anica Eschler ${ }^{1 *}$ (D), Georg Gradl ${ }^{2}$, Annekatrin Wussow ${ }^{1}$ and Thomas Mittlmeier ${ }^{2}$
}

\begin{abstract}
Background: All diabetic neuroosteoarthropathy (Charcot arthropathy) treatment concepts are focused on a long-term infection-free, ulcer-free, and plantigrade sufficiently stable foot in order to avoid amputation. Reconstructive arthrodesis techniques for severe deformities are associated with high postoperative complication rates. This study reports a detailed complication analysis and provides a strategy that may help detect patients at risk for a complicated postoperative course.
\end{abstract}

Methods: The study comprised 43 feet in 37 patients with severe non-plantigrade or unstable Charcot deformity, Eichenholtz stages II/III (Sanders and Frykberg types II-V), who underwent reconstructive arthrodesis of the mid- and/or hindfoot. Patients were retrospectively enrolled 4.5 years postoperatively (range 1.8-11.2 years). All patients showed at least two out of five positive Pinzur high-risk criteria (immuno-compromising illnesses, large bone deformity, longstanding ulcer overlying infected bone, regional osteopenia, obesity). Follow-up included a detailed clinical analysis and radiologic assessment with emphasis on complication analysis and evaluation in accordance to the PEDIS classification system.

Results: Significantly lower overall complication rates, as well as re-operation, reulceration and amputation counts were found for patients with a cumulative PEDIS count below 7. For PEDIS single criteria, significantly lower overall complication rates were found for patients without signs of occlusive peripheral artery disease, an ulcer extent $<0.9 \mathrm{~cm}^{2}$, ulcer depth including erosion and inflammation of the skin and subcutaneous tissues only. Soft-tissue complications affected $49 \%$ of patients, hardware breakage $33 \%$, hardware loosening $19 \%$, non-union $18 \%$ and amputation $21 \%$. Radiographs revealed a correct reconstruction and restoration of all foot axes postoperatively with partial recollapse at the lateral foot column; however, fixation strength for the medial column was maintained.

Conclusions: Internal corrective arthrodesis for patients within the deformed stages of Charcot deformity can provide adequate reconstruction, as assessed by intraoperative radiographic measures, that exhibit superior long-term stability for the medial column. Despite a high risk patient population, a favourable outcome in terms of overall complication, re-ulceration, and amputation rates for patients/feet with a cumulative PEDIS count below 7 was found. The cut-off value of 7 may aid clinical decision-making during preoperative planning for Charcot deformity.

Keywords: Charcot feet, Diabetic neuroosteoarthropathy, DNOAP, Corrective arthrodesis, Surgical treatment, Complications, Diabetes mellitus, PEDIS classification

\footnotetext{
* Correspondence: anica.eschler@med.uni-rostock.de

'Department of Trauma, Hand and Reconstructive Surgery, University of

Rostock, Medical Center, Schillingallee 35, D-18057 Rostock, Germany

Full list of author information is available at the end of the article
}

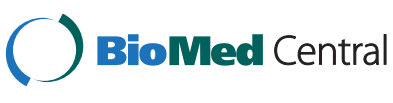

(c) 2015 Eschler et al. Open Access This article is distributed under the terms of the Creative Commons Attribution 4.0 International License (http://creativecommons.org/licenses/by/4.0/), which permits unrestricted use, distribution, and reproduction in any medium, provided you give appropriate credit to the original author(s) and the source, provide a link to the Creative Commons license, and indicate if changes were made. The Creative Commons Public Domain Dedication waiver (http://creativecommons.org/publicdomain/zero/1.0/) applies to the data made available in this article, unless otherwise stated. 


\section{Background}

The aim of any treatment concept involving neuroosteoarthropathy (Charcot arthropathy) for diabetic or other neuropathic diseases is a long-term infection-free, ulcer-free, and sufficiently plantigrade stable foot in order to maintain the ability to walk independently and avoid amputation [1, 2]. The search for the ideal treatment strategy is a challenge for foot and ankle specialists; furthermore, general evidence-based treatment algorithms are lacking and the literature is inconsistent regard to both the ideal treatment option and treatment timing because of the disease's unrelenting progression. The disease progression may lead to a loss of osteoligamentous architecture and consequently loss of the plantigrade foot alignment; thus, inducing subsequent soft tissue complications such as skin breakdown, recurrent ulcerations, and infections $[1,3]$. Neuroosteoarthropathic patients with chronic ulceration have a 12 times higher risk of amputation, compared to those with ulcer-free feet [4]. Ulceration characteristics are described by the widely-used PEDIS classification system developed by the International Working Group on Diabetic Foot (IWGDF) [5, 6]. It describes five specific ulcer criteria; perfusion, extent, depth/tissue loss, infection, and sensation; each criterion is graded by severity (Fig. 1).

With non-operative treatment with total contact casts or walkers, a long-term ulcer-free foot can be achieved

\begin{tabular}{|c|c|c|}
\hline & Grade & Symptoms \\
\hline \multirow[t]{3}{*}{ Perfusion } & $\mathbf{P 1}$ & No symptoms/signs of PAD \\
\hline & $\mathbf{P 2}$ & Symptoms/signs of PAD, but not of CLI \\
\hline & P3 & CLI \\
\hline Extend/size & $\mathbf{E}$ & Wound size (measured in square centimetres) \\
\hline \multirow[t]{3}{*}{ Depth/tissue lost } & D1 & $\begin{array}{l}\text { Superficial full thickness ulcer, not penetrating any } \\
\text { structure deeper than the dermis }\end{array}$ \\
\hline & D2 & $\begin{array}{l}\text { Deep ulcer, penetrating below the dermis to } \\
\text { subcutaneous structures, involving fascia, muscle, or } \\
\text { tendon }\end{array}$ \\
\hline & D3 & $\begin{array}{l}\text { All subsequent layers of the foot involved, including } \\
\text { bone and/or joint (exposed bone, probing to bone) }\end{array}$ \\
\hline \multirow[t]{4}{*}{ Infection } & I1 & No symptoms or signs of infection \\
\hline & $\mathbf{I 2}$ & $\begin{array}{l}\text { Infection involving the skin and the subcutaneous tissue } \\
\text { only (without involvement of deeper tissues and without } \\
\text { systemic signs); at least } 2 \text { of the following items are } \\
\text { present: } \\
\text { - local swelling or induration, } \\
\text { - erythema > } 0.5 \text { to } 2 \mathrm{~cm} \text { surrounding the ulcer } \\
\text { - local tenderness or pain } \\
\text { - local warmth } \\
\text { - purulent discharge }\end{array}$ \\
\hline & $\mathbf{I 3}$ & $\begin{array}{l}\text { Erythema }>2 \mathrm{~cm} \text { plus one of the items described above } \\
\text { or infection involving structures deeper than skin and } \\
\text { subcutaneous tissues (abscess, osteomyelitis, septic } \\
\text { arthritis, fasciitis) without systemic inflammatory } \\
\text { response signs }\end{array}$ \\
\hline & I4 & $\begin{array}{l}\text { Any foot infection with the following signs of a SIRS } \\
\text { manifested by two or more of the following conditions: } \\
\text { - Temperature }>38 \text { or }<36 \text { Celsius } \\
\text { - Heart rate }>90 \text { beats } / \mathrm{min} \\
\text { - Respiratory rate }>20 \text { breaths } / \mathrm{min} \\
\text { - PaCO } 2<32 \mathrm{~mm} \mathrm{Hg} \\
\text { - White blood cell count }>12,000 \text { or }<4,000 / \mathrm{cu} \mathrm{mm} \\
\text { - } 10 \% \text { immature (band) forms }\end{array}$ \\
\hline \multirow[t]{2}{*}{ Sensation } & S1 & No loss of protective sensation \\
\hline & $\mathbf{S 2}$ & $\begin{array}{l}\text { Loss of protective sensation with absent pressure } \\
\text { sensation on } 2 \text { of } 3 \text { sites on the plantar side of the foot or } \\
\text { absent vibration sensation or vibration threshold }>25 \mathrm{~V} \\
\text { on the hallux }\end{array}$ \\
\hline
\end{tabular}

Fig. 1 PEDIS classification system according to IWGDF Guidelines (International Working Group on the Diabetic Foot [5, 6]). Legend: PAD: peripheral arterial disease; CLI: critical limb ischemia; SIRS: systemic inflammatory response syndrome 
in approximately $60 \%$ of patients if plantigrade foot alignment can be established (early stage I/II applying the Eichenholtz classification system) [1]. Patients with an advanced degree of deformity and mid- and/or hindfoot instability experience less favourable results after non-operative treatment. Multiple recastings and prolonged disability are the consequences, and 40-51\% of Charcot patients may need surgical treatment at some point in the disease's progression $[1,7,8]$. At this time point, when signs of instability and progressive malalignment are present, reconstruction arthrodesis techniques are indicated $[1,9,10]$. Reconstruction arthrodesis techniques vary from external fixation techniques such as ring fixators to internal fixation techniques such as plates, screws, or bolts (or combinations of these techniques) $[1,2,9,11,12]$. Due to the absence of general algorithms, the treatment option is usually determined by individual patient factors and the surgeon's expertise [1].

For surgery in Charcot disease patients, prolonged healing periods, high rates of infectious complications, non-union and malunion, stress fractures, fixation failure, metal-induced soft-tissue irritation, implant breakage or loosening, and concomitant high re-operation rates are frequently described $[1,7,11-18]$. Due to these multiple disadvantages, in 2007 Pinzur et al. [1, 15] proposed that patients with high risk criteria such as a large bone deformity, an longstanding ulcer overlying infected bone, regional osteopenia, obesity, or immunocompromising illnesses do not qualify for open reduction and internal fixation. Instead, in these cases, percutaneous correction and fixation with an external ring fixator is recommended. Only in cases of available low-risk criteria (no open wounds, no history of deep infection, good bone quality, minimal diabetes-associated comorbidity, no morbid obesity), internal corrective arthrodesis is recommended $[1,15]$. However this recommendation was based on the experience of one single surgeon and no detailed algorithm was provided [1]. Thus, it remains unclear how many high- or low-risk criteria are applicable to achieve the desired outcome.

In view of the foregoing, we retrospectively evaluated a consecutive series of neuroosteoarthropathic patients who underwent corrective arthrodesis of late stage Charcot mid- and hind-foot neuroosteoarthropathy with at least two out of the five positive Pinzur high-risk criteria. A 4.5 years follow-up was conducted to determine whether internal corrective arthrodesis could provide the desired outcome of a foot that was infection-free and ulcer-free for a long period, despite the presence of positive high risk criteria. The results were then quantified based on the PEDIS criteria in order to evaluate those patients that may qualify for internal corrective arthrodesis despite Pinzur high-risk criteria.

\section{Methods}

The study comprised 43 feet in 37 patients with severe Charcot neuroosteoarthropathy who underwent internal corrective arthrodesis from November 2005 to March 2012 and were retrospectively reviewed. The indication criteria for corrective arthrodesis were: (1) a clinically and radiographic non-plantigrade foot alignment; (2) a high degree of instability of the medial or/and lateral midfoot and/or hindfoot region proven by clinical examination and visualized by the changes of radiologic axes as described by Sammarco et al. [19]: positive talar-first metatarsal angle in anterior-posterior (AP) views, negative talar-first metatarsal angle in lateral views, negative calcaneal-fifth metatarsal angle in lateral views, and deviations from the neutral axis in Saltzman views; (3) the foregoing, plus clinically manifest or impending ulceration of soft tissues overlying bony deformity; and (4) failed primary conservative treatment.

The mean patient age ( 24 males; 13 females) was $56.7 \pm$ 8.5 years (range 29-76). All but two patients suffered from type 2 diabetes $(n=31)$ or type 1 diabetes $(n=4)$ with insulin dependency in $94 \%$ of the cases $(n=33)$. Twentyeight patients $(76 \%)$ suffered from three or more than three secondary diagnoses. Thirty-three feet (77\%) were operated during the consolidation phase (Eichenholtz stage III). Ten feet (23\%) presented with stage II arthropathy (coalescence). Applying the topographic classification, according to Sanders and Frykberg, a mid-foot affection type II and/or III, corresponding to the Lisfranc and Chopart joint region, was visible in all feet; however, 15 radiographs showed an additional involvement of the subtalar and talocalcaneal joints, according to Sanders and Frykberg type IV.

The preoperative assessment included anterior-posterior and lateral weight-bearing radiographs of the foot and ankle joint, including Saltzman views based on the following described angles. In case of doubt regarding the peripheral vascular status, color-coded duplex sonogram was performed before surgery to reveal patients with relevant macroangiopathy. Subsequently, angiographic dilatation and stenting was performed in two patients preoperatively.

The location of the corrective osteotomy and arthrodesis was determined according to radiologic and clinical assessment, and stabilization was performed using specific implants in order to achieve maximum stability. The procedure was as follows. A medial utility incision exposed the medial column as well as the talonavicular, naviculocuneiform, and tarsometatarsal joints for either osteotomy, excision of the bony deformity, or denuding the joint surfaces from cartilage was performed as well as resection of necrotic bone; this was done in preparation for fusion and reconstruction of a plantigrade foot position. Stabilization of the medial column was 
performed in 21 feet (49\%) using extramedullary devices, of which 9 feet $(21 \%)$ received angular stable plates and 9 feet $(21 \%)$ received intramedullary implants only. Seven feet $(16 \%)$ were stabilized using a combination of intra- and extra-medullary implants (Table 1). With isolated collapse of the medial column, the hindfoot and lateral foot region remained untouched. Additional stabilization of the lateral column was performed in 22 feet (51\%); 6 of these feet (14\%) were stabilized with angular stable plates. Hindfoot arthrodesis was performed in 16 cases (37\%) using compression screws $(n=9 ; 21 \%)$, angular stable plates $(n=6 ; 14 \%)$ or locking nails $(n=1 ; 2 \%)$. In order to reconstruct the osseous foot geometry, resection of the necrotic midfoot/hindfoot bones was necessary in 7 feet (16\%). In 30 cases (70\%), osseous defects were filled with autologous iliac crest grafts. One case (2\%) required lengthening of the gastrocnemius-soleus complex. In 3 cases (7\%), Achilles tendon lengthening via the Dockery technique was performed as indicated by intraoperative evaluation of tightness of the Achilles and gastrocnemius tendon complex.

Postoperatively, a lower leg splint was applied and replaced by a total contact cast with soft tissue consolidation. Mobilization was performed with partial weightbearing of $20 \mathrm{~kg}$ if possible. Routine follow-up e.g., for cast replacement and radiographs, was conducted two weeks after hospital discharge and then at monthly intervals until radiographic bony consolidation was proven. Subsequently annual follow-up visits were established. Follow-up ended if amputation occurred. Mean follow-up averaged $4.5 \pm 6.6$ years (range 1.8-11.2).

Table 1 Surgical procedures performed on study group patients

\begin{tabular}{llll}
\hline Surgical approach/ & & All & \\
\cline { 3 - 4 } Point of stabilization & & $\mathrm{N}$ & $\%$ \\
\hline Medial column & All & 37 & 86 \\
& Extramedullary & 21 & 49 \\
& Intramedullary & 9 & 21 \\
& Combined & 7 & 16 \\
& All & 22 & 51 \\
Lateral column & Standalone & - & - \\
& Combined to medial column/ & 22 & 51 \\
Hindfoot & hindfoot stabilization & & \\
& All & 16 & 37 \\
& Standalone & 6 & 14 \\
& Combined to medial/lateral & 11 & 26 \\
Additive osseous & column stabilization & & \\
resection & & 7 & 16 \\
Additive autologous & & & \\
iliac crest graft & & 30 & 70 \\
\hline
\end{tabular}

The 4.5 years follow-up included a detailed failure analysis for the peri- and post-operative time period, focusing on complication and re-operation rates. Therefore, early (30 days postoperatively), intermediate ( 30 days to 5 months postoperatively) and late complications (from postoperative month 6 onward) were recorded and assessed according to their degree of severity and the need for either further surgery or conservative regime. All patients were then graded according to the PEDIS classification system $[5,6,20]$ and Pinzur criteria $[1,15]$. The former, developed by the International Working Group on the Diabetic Foot (IWGDF), describes the diabetic foot depending on severity of the following characteristics: lower leg/foot perfusion, ulcer extent, ulcer depth/tissue loss, infection, and sensation $[5,6,20]$. The latter, published by Pinzur in 2007 [1, 15], distinguishes high-risk criteria as a large bone deformity, a longstanding ulcer overlying infected bone, regional osteopenia, obesity, or immuno-compromising side illnesses, as well as low-risk criteria such as absence of open wounds, no history of deep infection, good bone quality, minimal diabetes-associated comorbidity, and absence of morbid obesity. On the basis of this Pinzur grouping $[1,15]$ and PEDIS criteria $[5,6,20]$ a complication analysis was performed with the goal of evaluating those patients at risk who do not qualify for internal corrective arthrodesis. Furthermore, patient mobilization and casting length were registered.

A detailed radiologic follow-up included measurement of the AP talar-first metatarsal angle, lateral talar-first metatarsal angle, calcaneal-fifth metatarsal angle, dorsal midfoot displacement in pre-, post- and follow-up radiographs. The mean values are given in absolute numbers representing the change of angulation for the AP talarfirst metatarsal angle; however, the range is given with algebraic signs; thus, negative values correspond to abduction deformity and positive values correspond to adduction deformity of the forefoot. Twenty-nine feet were available with complete radiologic follow-up.

\section{Ethics, consent and permissions}

The study was approved by the local ethical committee under the document no. A 2014-0174 (2014/11/27) and is in accordance with the declaration of Helsinki. All patient's gave consent to participate.

\section{Statistical analysis}

Results are given as mean \pm SEM (range). After satisfying the assumption of normality (Kolmogorov), the paired $t$-test analysis or the Mann-Whitney $U$ Test (non-normal distribution) were performed to analyse the differences in radiographic parameters. For differences in complication rates, according to preoperative PEDIS single criteria ("P" perfusion, "E" extent, "D" depth, "I" 
infection, "S" sensation); cumulative PEDIS count groups were developed and a paired $t$-test analysis was performed. Complication counts, re-operation and reulceration rates, amputation counts, and length of immobilization were analysed in relation to the cumulative PEDIS count by comparing the group below the boundary value as defined above and hereafter. The boundary value was initially set as the cumulative PEDIS mean value $(6.5 \pm 2.3)$, then, one SEM value (8.8) was added to the mean value, and then two SEM values (11.1) were added to the mean value. Significance was defined at $p<0.05$. For assessment of complications, reoperation, re-ulceration, number of amputations, and length of immobilization dependent upon lower leg/foot perfusion, P1 was compared to P2 and P3. Dependent upon the depth of ulceration, D1 was compared to D2 and D3 (and D1 and D2 were compared to D3). Dependent upon the presence of local infection, I1 was compared to I2, I3, and I4 (and I1 and I2 were compared to I3 and I4). Sensation was not further considered since all patients showed a loss of protective sensation (S2). For the ulcer extent, results were compared based on the cumulative PEDIS value (ulcer extent as mean $0.9 \pm$ $0.2 \mathrm{~cm}^{2}$ ). Statistical analysis was performed using IBM SPSS Statistics version 20.0 software (Armonk, New York, USA).

\section{Results}

\section{Complication analyses}

All patients/feet showed a minimum of 2 out of 5 positive Pinzur high-risk criteria (mean $3.1 \pm 0.1$; range 2-5, Fig. 2). According to Pinzur [15], all feet were at high risk for postoperative complications. The following complication analyses focused on soft tissue complications, implant associated complications, non-union (stable/ non-stable) and amputation; these complications were determined during the first run of the analyses. Almost half ( 20 of 43 feet; $46.5 \%$ ) developed a mean $0.51 \pm 0.1$ early complications, 26 feet $(61.0 \%)$ developed intermediate complications (mean $0.81 \pm 0.1$ ), and 31 feet (72.1\%) developed late complications (mean $1.79 \pm 0.2$ ).

Soft tissue complications occurred in 34 feet (79 \%) of 29 patients $(67 \%)$ during the follow-up period. Specifically, 21 feet (49\%) developed superficial wound infections, 16 feet (37\%) developed (re)ulceration, and 15 feet (35\%) had impaired wound healing. Osteomyelitis affected 4 feet $(9 \%)$. About half $(52 \% ; n=40)$ of the soft tissue complications occurred during the late follow-up phase, $27 \%(n=21)$ developed within the early phase, and $21 \%(n=16)$ occurred within the intermediate phase.

Hardware-associated complications affected 22 feet (51\%) of 21 patients (49\%); hardware breakage, which might affect single screws, occurred in 14 feet (33\%) and hardware loosening occurred in 8 feet (19\%). In 8 feet $(18 \%)$, non-union of the arthrodesis region was observed. Both hardware-associated complications and non-union occurred most frequently in the late phase (54\%); however, $42 \%$ were observed within the intermediate phase.

Amputation had to be performed on 9 patients (21\%), with a need for lower leg amputation in 6 cases (14\%), forefoot Chopart amputation in one case $(2 \%)$, and toe amputation in 2 cases (5\%). Amputation was performed at a mean $1.1 \pm 0.8$ years (range $0-3$ ) after initial surgery.

For complication management, $1.9 \pm 4.0$ (range 0-5; $64 \%)$ complications of a mean $2.9 \pm 3.5$ complications (range $0-7, n=131$ ) had to be resolved surgically. In 14 cases (33\%), only minor revision surgery such as softtissue debridement or jet lavage were necessary. In 20

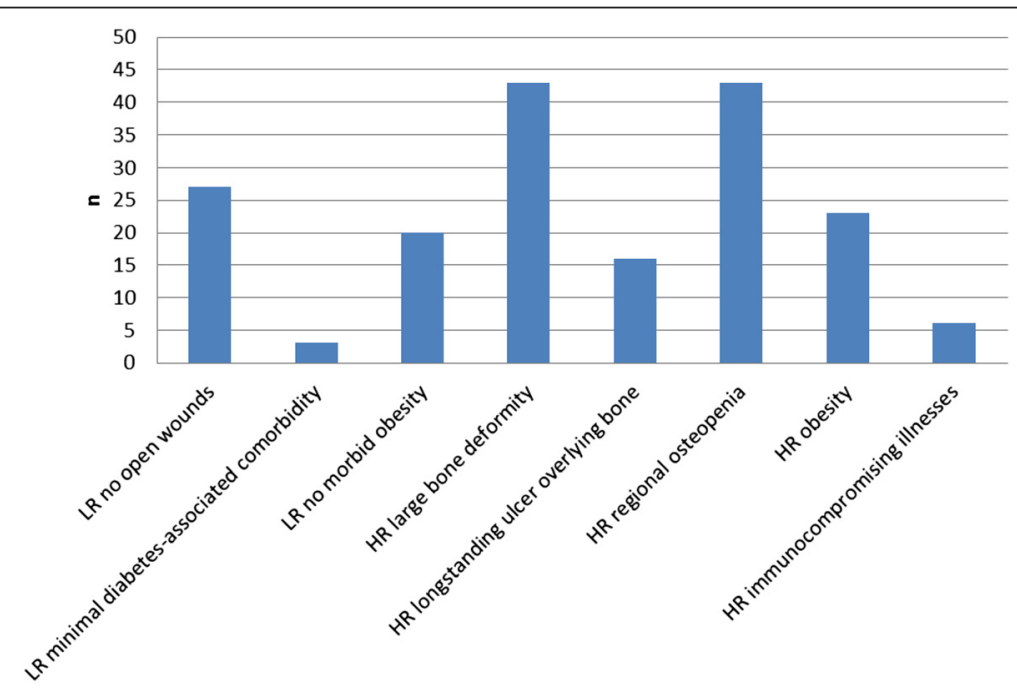

Fig. 2 Classification according to Pinzur's criteria [1, 15] 
cases (47\%), major surgery as rearthrodesis or amputation was performed, among which 16 cases (37 \%) underwent minor revision surgery during follow-up as well (Table 2). This resulted in a mean of $3.1 \pm 5.0$ (range $0-10$ ) revision surgeries. Regarding the time point of complication resolution, $18 \%$ of early complications, $25 \%$ of intermediate complications, and $57 \%$ of late complications required surgical complication management.

\section{Complication analyses considering PEDIS criteria}

Taking into consideration the preoperative cumulative PEDIS count and the single PEDIS criteria (Fig. 1), a differentiated analysis was performed to ascertain those high-risk patients who qualify for internal corrective fixation techniques, despite a Pinzur high risk rating.

The mean cumulative PEDIS count accounted for $6.5 \pm 2.3$ (range $0-14$ ). When comparing the groups with $\geq 7$ and $<7$ cumulative PEDIS counts, a significantly lower overall complication rate for the $<7$ group $(p<0.01)$, as well as a significant lower re-operation $(p<0.05)$, re-ulceration $(p<0.03)$ and amputation counts $(p<0.01)$ were revealed (Fig. 3a). By differentiating early, intermediate, and late complications only the latter (late) were significantly reduced $(p<0.01)$. When adding one SEM to the mean value $(6.5+2.2=8.8)$; thus, comparing the groups $\geq 9$ and $<9$, cumulative PEDIS value analogue results were achieved as shown in Fig. 3b. Only the criterion of re-ulceration showed non-significant results. When adding two SEM to the mean value $(8.8+$ $2.2=11.0$ ); thus, comparing the groups $\geq 11$ and $<11 \mathrm{cu}-$ mulative PEDIS values, no significant differences were found. This reveals a higher risk for complications among patients with a cumulative PEDIS count $\geq 7$.

The analyses of PEDIS under the single criterion of perfusion ("P") showed a significantly lower overall complication rate when no symptoms or signs of peripheral artery occlusive disease (PAD) were apparent when compared to feet with symptoms or signs of PAD or manifest critical limb ischemia (CLI) (P1 vs. P2 and P3; $p<0.05$; Fig. 4). In addition, apparent complications

Table 2 Type of revision surgery performed on study patients

\begin{tabular}{|c|c|c|c|c|c|c|c|c|}
\hline \multirow[t]{2}{*}{ Revision surgery } & \multicolumn{2}{|l|}{ All } & \multicolumn{2}{|c|}{ Early } & \multicolumn{2}{|c|}{ Intermediate } & \multicolumn{2}{|c|}{ Late } \\
\hline & $n$ & $\%$ & $\mathrm{n}$ & $\%$ & $\mathrm{n}$ & $\%$ & $\mathrm{n}$ & $\%$ \\
\hline Corrective Arthrodesis & 24 & 55.8 & 1 & 2.3 & 7 & 16.3 & 16 & 37.2 \\
\hline Local osseous resection & 2 & 4.7 & - & - & 1 & 2.3 & 1 & 2.3 \\
\hline Implant removal & 18 & 41.9 & - & - & 10 & 23.3 & 8 & 18.6 \\
\hline Amputation & 9 & 20.9 & 1 & 2.3 & 2 & 4.7 & 6 & 13.9 \\
\hline Others $^{\mathrm{a}}$ & 34 & 39.1 & 14 & 16.1 & 4 & 4.6 & 16 & 18.4 \\
\hline
\end{tabular}

${ }^{a}$ soft tissue debridement, jet lavage, antibiotic chain placement/replacement, haematoma evisceration, split-skin grafting, closed amputation, muscle or musculocutaneous flaps, fracture osteosynthesis were significantly more amenable to successful conservative treatment $(p<0.05)$.

For the ulcer extent ("E"; $8.8 \pm 0.2 \mathrm{~cm}^{2}$; range $0-6$ ), significantly lower overall complication rates $(p<0.01)$ and amputation rates $(p<0.05)$ were found for a preoperative ulcer extent of $<0.9 \mathrm{~cm}^{2}$. Again, apparent complications were significantly more amenable to successful conservative treatment $(p<0.05)$.

Applying the criterion of ulcer depth/tissue loss ("D") significantly lower overall complication rates $(p<0.01)$, reoperation rates $(p<0.03)$ and amputation rate $(p<0.01)$ were found with the comparison of superficial fullthickness ulcers/erosions (grade 1) to ulcers penetrating below the dermis (grade 2) or ulcers penetrating all deeper layers of the foot, including bone/joints (grade 3) (D1 was compared to D2 and D3). Again, apparent complications were significantly more amenable to successful conservative treatment $(p<0.01)$.

The criterion of infection ("I") revealed significant results in all parameters when comparing feet with no signs of infection (I1) to any signs of infection (I2, I3 and I4), complication rate $(p<0.01)$, re-operation rate $(p<0.01)$, re-ulceration rate $(p<0.01)$, and amputation rate $(P<0.05)$. Comparing those with inflammation of the skin and subcutaneous tissue (I1 and I2) to those with extensive erythema deeper than the skin and subcutaneous tissue (I3), only the overall complication rate reached persistent significant differences $(p<0.01)$.

\section{Radiological results}

The mean talar-first metatarsal angle in an AP view of the foot, as an indicator for abduction/adduction midfoot deformity, improved from $8.4 \pm 4.2^{\circ}$ (range -17 to +31 ) preoperatively to $4.6 \pm 3.3^{\circ}$ (range -8 to +23 ) postoperatively, but slightly decreased to $5.6 \pm 3.9^{\circ}$ (range 24 to +17 ) at final follow-up. An effective $3.8 \pm 5.5^{\circ}$ (range -11 to +22 ) correction to the neutral $\left(0^{\circ}\right)$ axis was achieved postoperatively; it decreased slightly to $2.8 \pm 6.5^{\circ}$ (range -18 to +41 ) at final follow-up. Full correction to the anatomic neutral position $\left(0^{\circ}\right)$ axis was observed in $83 \%(n=24)$ of the feet. In $38 \%$ of patients $(n=11)$ an overcorrection with change of algebraic sign was observed. Due to the observed recollapse, $66 \%(n=19)$ of patients showed correct AP talarfirst metatarsal angle at final follow-up (Table 3).

The mean lateral talar-first metatarsal angle showed significant improvements of $+15.0 \pm 7.6^{\circ}$ (range: -9 to $+34 ; p<0.01$ ) postoperatively, compared to preoperative values. At final follow-up an improvement of $+6.6 \pm 7.7^{\circ}$ (range -33 to +18 ; $p<0.01$ ) was found; this loss of reduction was significant. Ideally, the intraoperative change of the lateral talar-first metatarsal angle exhibited a high positive value, corresponding to a change from a valgus deformity to a neutral axis, therefore, erection of the foot arch. This was achieved in $96.6 \%(n=28)$ of 

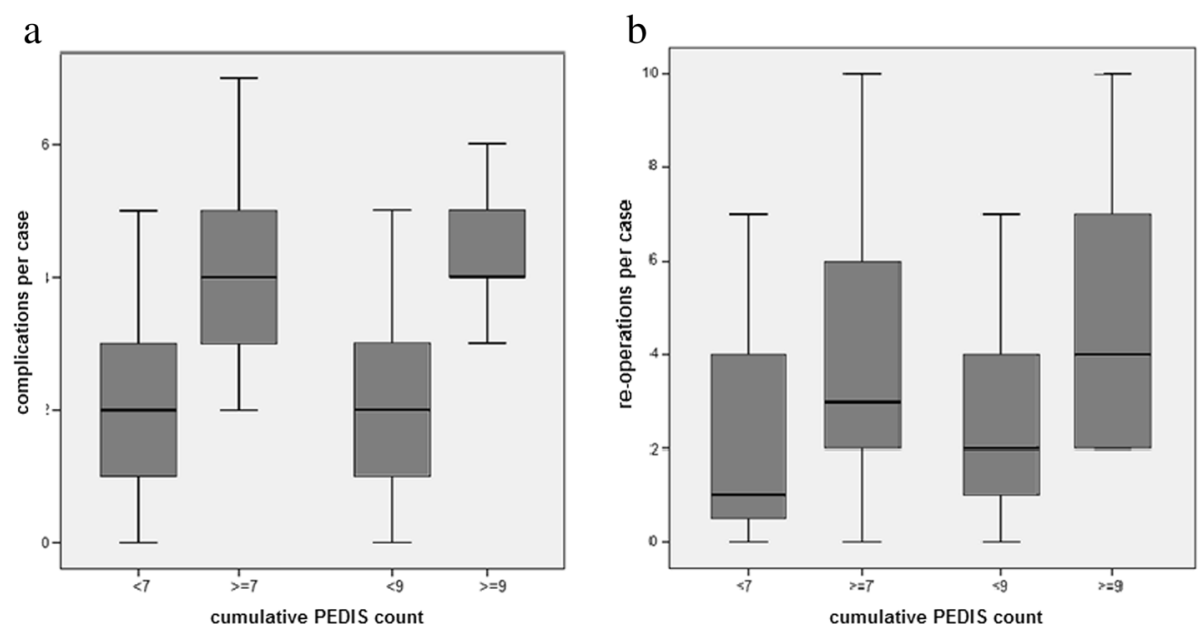

Fig. 3 Overall complication rates (a) and re-operation rates (b) according to the cumulative PEDIS count [5, 6; Fig. 1]

the patients postoperatively and was still observed in $62.1 \%(n=18)$ at final follow-up.

The calcaneal-fifth metatarsal angle in the lateral view displaying the lateral foot arch is optimally erected to intraoperative positive values. The calcaneal-fifth metatarsal angle improved significantly with $+7.2 \pm 7.1^{\circ}$ (range -8 to $+22 ; p<0.01$ ) when the pre- and post-operative values in our study population were compared; however, it decreased to $-1.8 \pm 8.9$ (range -16 to +16 ; $p<0.01)$ at final follow-up, thus, denoting a recollapse of the lateral foot arch in mean. However, postoperatively, $93 \%(n=26)$ of patients showed correct reduction of the lateral foot arch, and ultimately, $35 \%(n=10)$ showed correct reduction at final follow-up.

Since standard angles on lateral radiographs tend to underestimate the grade of deformity with midfoot joint displacement [19], the dorsal midfoot displacement (lateral view $\mathrm{x}$-ray; the vertical distance at the level of dislocation between the talar midline axis and the first metatarsal axis) was measured. Dorsal midfoot displacement showed significant postoperative improvements of $+9.5 \pm 9.2 \mathrm{~mm}$ (range -9 to $+32 ; p<0.01$ ) and slight bone loss; however, a $+5.9 \pm 9.4 \mathrm{~mm}$ correction (range 22 to $+26 ; p<0.05$ ) was observed at final follow-up. This means that in $83 \%(n=24)$ of the patients postoperatively, and ultimately $59 \%(n=17)$ at final follow-up achieved adequate correction.

\section{Hospitalization and mobilization}

Mean hospitalization duration following the initial surgery was $28.3 \pm 14.4$ days; the minimum duration of stay was 8 days, the maximum 87 days caused by a very complicated course of one patient. The mean postoperative casting period was $2.5 \pm 3.7$ months (range $0.3-7$ months).
At final follow-up, $60 \%$, of the patients $(n=26)$ were fully mobile without a need for walking aids; 7 patients (16\%) used non-orthopaedic shoes and 19 patients (44\%) used orthopaedic shoes. Therefore, the goal of long-term walking independence was reached. Seven patients $(16 \%)$ wore a prosthesis. Only 1 patient $(2 \%)$ used a wheelchair, 2 patients $(5 \%)$ used a walker, and 5 patients $(12 \%)$ used a cane.

\section{Discussion}

For diabetic neuroosteoarthropathy treatment general evidence-based treatment algorithms are lacking and the literature is inconsistent regarding both the ideal treatment type and timing of treatment due to its unrelenting progression. With disease progression and unstable nonplantigrade alignment of the mid- and hind-foot, a high degree of skin breakdown and ulceration at the site of bony deformities occurs $[1,3]$. Pinzur $[1,8]$ and other authors $[21,22]$ proposed the main goals: an infectionfree and ulcer-free foot for a long duration together with the ability to use commercially-available depth-inlay shoes and custom-accommodative foot orthoses for maintaining long-term walking independence. Nonsurgical measures such as total contact casting represent the treatment option of choice in cases of plantigrade foot positioning [19, 23, 24]. However, the progressive character of instability is associated with a serious impairment of the quality of life and an estimated risk of up to $49 \%$ to develop recurrent ulceration together with a high risk for further complications such as infections or eventually amputation [23, 25]. Therefore, early reconstructive surgery is suggested by several authors as a valuable treatment option in the presence of severe deformity [25-28]. Evidence-based literature does not exist, but clinical reports stress that stability can be restored with precise surgical technique, appropriate 


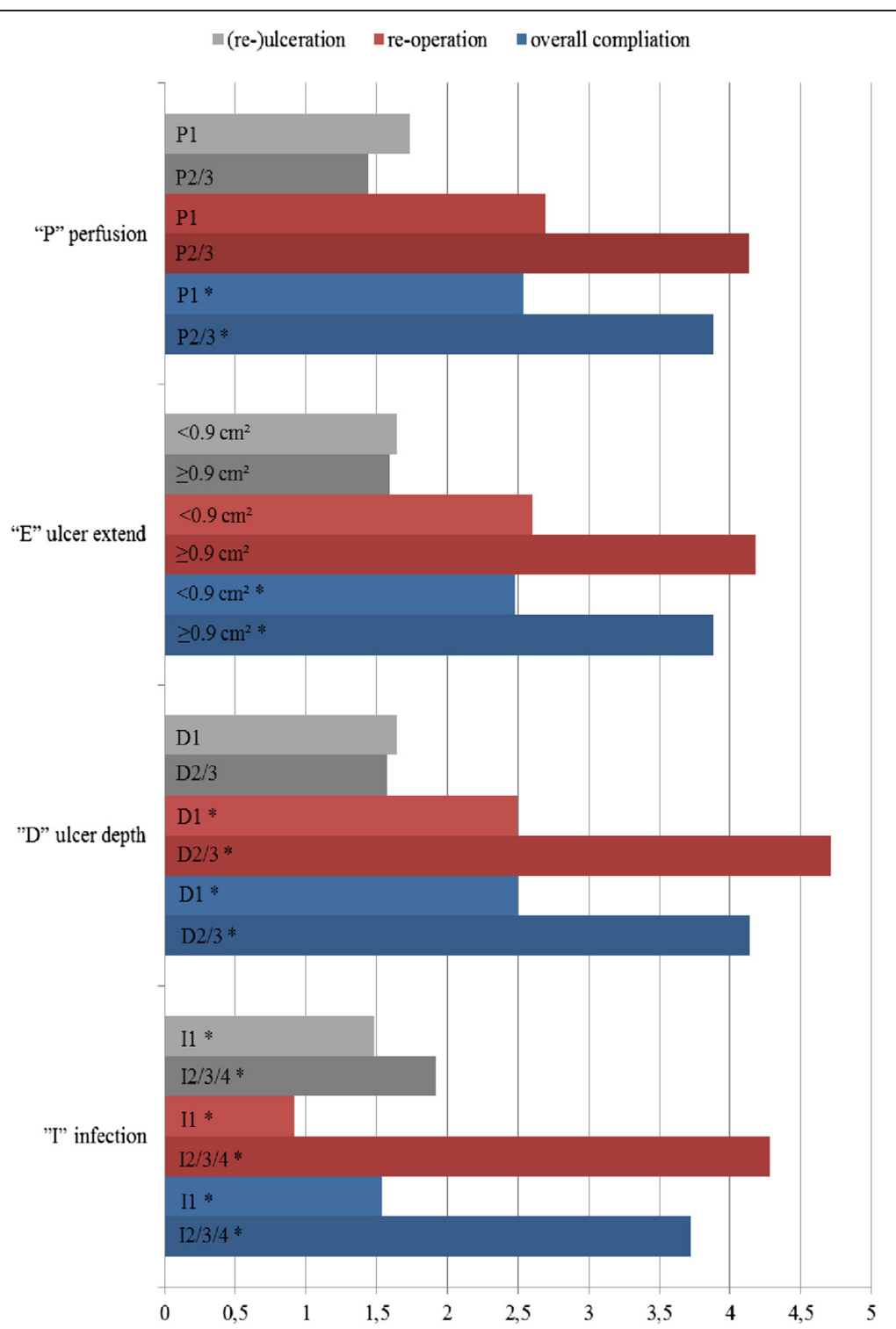

Fig. 4 Complication evaluation applying the PEDIS classification system [5, 6]. Legend: * ${ }^{*}$ ignificant values $(p<0.05)$

perioperative education, and postoperative therapy (assuming adequate patient compliance) [2, 27]. Nevertheless, according to Pinzur [1], certain high-risk criteria such as a large bone deformity, a longstanding ulcer overlying infected bone, regional osteopenia, obesity, or immunocompromising illness showed increased complication rates and therefore interfere with open reduction and internal fixation. Instead, percutaneous correction and fixation with an external ring fixator is recommended for high-risk constellations

In patients with low-risk criteria, internal corrective arthrodesis is recommended [1]. Low-risk criteria include absence of open wounds, no history of deep infection, good bone quality, minimal diabetes-associated comorbidity, and absence of morbid obesity. Actually, the diagnosis of Charcot deformity is frequently delayed and only made in the deformed stages [29]. Conversely, despite prompt immobilization and protected weightbearing, some patients develop severe deformities [29].

We retrospectively reviewed 43 feet with a deformation stage consistent with Charcot disease and determined as a high-risk group, which had at least two positive high-risk criteria according to Pinzur [1]. During a 4.5 years follow-up, a detailed complication analysis was performed which revealed high complication rates. The early postoperative period was characterized by soft tissue complications in which $75 \%$ of patients were affected by immediate postoperative wound infections (47 \%); this finding may be attributable to the endangered diabetic patient population [3] and concurs with 
Table 3 Radiographic evaluation

\begin{tabular}{|c|c|c|c|c|c|c|}
\hline Radiographic angle & & mean & $\min$ & Max & SEM & $p^{*}$ \\
\hline \multirow[t]{5}{*}{ talar-first metatarsal angle (AP) ${ }^{a}$} & pre-surgery & 8.4 & -17.1 & 30.8 & 4.2 & \\
\hline & post-surgery & 4.6 & -7.9 & 23.0 & 3.3 & \\
\hline & final follow-up & 5.6 & -23.5 & 17.0 & 3.9 & - \\
\hline & Correction post-surgery & 3.8 & -10.7 & 21.8 & 5.5 & \\
\hline & Correction final follow-up & 2.8 & -17.5 & 40.6 & 6.5 & \\
\hline \multirow[t]{5}{*}{ talar-first metatarsal angle (lat.) ${ }^{a}$} & pre-surgery & -12.5 & -28.5 & 14.9 & 8.8 & \\
\hline & post-surgery & 2.5 & -11.8 & 28.1 & 7.3 & \\
\hline & final follow-up & -5.9 & -28.2 & 18.5 & 8.8 & ${ }^{*} \mathrm{a}<0.01,{ }^{*} \mathrm{~b}<0.01,{ }^{*} \mathrm{~d}<0.01$ \\
\hline & Correction post-surgery & 15.0 & -9.2 & 33.8 & 7.6 & \\
\hline & Correction final follow-up & 6.6 & -33.2 & 17.5 & 7.7 & \\
\hline \multirow[t]{5}{*}{ calcaneal-fifth metatarsal angle lat.) $^{a}$} & pre-surgery & 10.8 & -8.1 & 29.0 & 7.5 & \\
\hline & post-surgery & 18.0 & 0.1 & 40.7 & 6.9 & \\
\hline & final follow-up & 9.0 & -11.8 & 33.0 & 5.2 & ${ }^{*} \mathrm{a}<0.01,{ }^{*} \mathrm{~b}<0.01,{ }^{*} \mathrm{~d}<0.01$ \\
\hline & Correction post-surgery & 7.2 & -7.9 & 21.5 & 7.1 & \\
\hline & Correction final follow-up & -1.8 & -15.5 & 15.6 & 8.9 & \\
\hline \multirow[t]{5}{*}{ dorsal midfoot displacement ${ }^{\mathrm{b}}$} & pre-surgery & 16.7 & 0.0 & 34.7 & 7.0 & \\
\hline & post-surgery & 7.2 & 0.0 & 28.7 & 4.3 & \\
\hline & final follow-up & 10.8 & 1.6 & 33.6 & 5.2 & ${ }^{*} \mathrm{a}<0.01,{ }^{*} \mathrm{c}<0.05$ \\
\hline & Correction post-surgery & 9.5 & -8.8 & 32.4 & 9.2 & \\
\hline & Correction final follow-up & 5.9 & -21.6 & 25.8 & 9.4 & \\
\hline
\end{tabular}

${ }^{*}$ significant values; *a pre-surgery vs. post-surgery' *b post-surgery vs. follow-up; *c pre-surgery vs. follow-up; *d correction post-surgery vs. correction final follow-up

a Values given in ${ }^{\circ}$

${ }^{b}$ Values given in $\mathrm{mm}$

rates of $7-26 \%$ reported by other studies with an mean of 2.5 years of follow-up [13, 23]. The osteomyelitis rate was $9 \%$ in our study population. It is reported to range from $12 \%$ to $16 \%$ after reconstructive surgery in other studies $[13,30]$. However, our osteomyelitis rate is markedly lower than the $33 \%$ osteomyelitis rate after conservatively-treated diabetic foot infections [31].

About one third (31\%) of the patients suffered from hardware breakage and $18 \%$ developed hardware loosening with consecutive non-union. Sammarco et al. [19] observed similar rates with $32 \%$ implant breakage in their 4.3 years of follow-up after midtarsal arthrodesis. A recent review [2], including 95 Level IV and V studies, revealed similar results and ulcer-free feet in most cases; however, it described a $22.4 \%$ non-union rate. Implant or technique-associated problems, as well as the prolonged healing period in the altered diabetic metabolism, are likely to be causal [32]. Nevertheless, currently there is consensus that even with incomplete union, an ulcerfree plantigrade foot may be achieved [2]. We also observed 9 cases (20\%) with amputation, resulting in an annual amputation rate of $4.4 \%$, which concurs with Saltzman et al. [25] who reported on a cohort of 115 patients with a mean of 3.8 years of follow-up; they found an annual amputation risk of $2.7 \%$ of cases without ulceration and an amputation risk of $28 \%$ in cases with ulceration. These cases incurred a $23 \%$ risk of requiring more than 18 months of casting and a high risk of about $49 \%$ for recurrent ulceration. In our study population, $36 \%$ of the patients suffered from recurrent ulcerations. Illgner et al. [11] reported on 205 patients with an external fixator and a follow-up period of 21 months; they found a $25 \%$ re-ulceration rate. A study of 115 conservatively treated patients with 3.8 years of follow-up by Saltzman et al. [25] showed $49 \%$ re-ulceration rates. Altogether, we observed 2.9 complications/foot leading to the question: "Can those patients at risk for a complicated postoperative course be detected in preoperative planning?".

In view of the foregoing we developed a potential predictor that would reveal those high-risk patients qualifying for internal corrective arthrodesis despite this risk. It was to take the PEDIS single group of criteria into account: feet without signs of PAD, an ulcer extent $<0.9 \mathrm{~cm}^{2}$, an ulcer depth up to erosion, and inflammation including only skin and subcutaneous tissue. This group of criteria alone showed significantly lower overall complication rates (P1, E1, D1, I2, (S)). For this 
degree of ulceration, the data also significantly predict lower amputation rates and for this degree of ulceration depth, they significantly predict lower amputation and reoperation rates. Since all factors but sensation showed significant influences on complication rates, we think that the cumulative PEDIS count rather than the PEDIS single criteria is practicable for clinical use because the former takes the entire patient into consideration. This study significantly revealed a favourable outcome in terms of overall complication, re-ulceration, and amputation rates for patients/feet with a cumulative PEDIS count below 7 . The cutoff value of 7 may aid clinical decision-making in preoperative planning for a Charcot deformity and an internal corrective arthrodesis. By implication, these results endorse the importance of early diagnosis for optimal treatment planning.

In regard to radiologic evaluation, the goal of reconstruction is to correct the non-plantigrade foot position and to establish a neutral AP tarso-first metatarsal angle, a positive lateral tarso-first metatarsal angle, a calcanearfifth-metatarsal angle, and a dorsal midfoot displacement correction to normal values. Correction was completely achieved in $83 \%$ of the AP talar-first metatarsal angle, in $97 \%$ of patients for the lateral talar-first metatarsal angle, $90 \%$ of patients for the calcaneal-fifth metatarsal angle and $83 \%$ of patients with dorsal midfoot displacement; these findings concur with those of other studies $[19,30]$. In addition, at final follow-up a significant recollapse of the longitudinal foot arch for both the medial column and, to a greater extent, the lateral column had to be observed in order to minimize the number of patients with persistent correction to $62 \%$ medially and $35 \%$ laterally. Correction of AP talar-first metatarsal angle recollapsed in $17 \%$ of feet. Recollapse of the midfoot, measured by the dorsal midfoot displacement, lowered radiographic success rates to $59 \%$ of the patients. Wiewiorski et al. [30] similarly experienced the worst recollapse rate for the lateral tarso-first metatarsal and calcanear-fifth-metatarsal angles. Those radiographic measurements reveal a good overall reliability for reconstructive techniques in our patient population. The significance of those radiographic measurements in regard to patient satisfaction is unknown [30]; this adds to the difficulty of radiographic evaluation, due to its putative measurement error, to determine weaknesses of this study. In addition, we noted another limitation: patient satisfaction was not evaluated in this study. This limitation is of significant importance. By forming groups based on clinically defined boundaries, heterogeneous cohorts may result, thus, leading to a statistical error. The study design was retrospective with specific inclusion criteria. Therefore, the limited patient sample negatively impacted generalizations.

\section{Conclusions}

Internal corrective arthrodesis in the more advanced stages of Charcot deformity can provide adequate reconstruction with intraoperative radiographic measurements. Superior stability was achieved for the medial column in this 4.5 years follow-up period with the lateral column showing less stability and a tendency to recollapse. Despite the favourable radiologic results, overall complication rates were high. A good predictor implementing Pinzur and PEDIS criteria was developed to identify those high-risk patients qualifying for uncomplicated internal corrective arthrodesis. Despite two-to-five positive Pinzur high-risk criteria, a favourable outcome in terms of overall complication, re-ulceration, and amputation rates for patients/feet with a cumulative PEDIS count below 7 was found. The cutoff value of 7 may aid clinical decision-making during preoperative planning for Charcot deformity and internal corrective arthrodesis.

\section{Competing interests}

The authors declare that they have no competing interests.

\section{Authors' contributions}

AE contributed to the study design, data collection, data analysis and interpretation and wrote the manuscript. GG contributed to study design and revision of the manuscript. AW contributed to data collection and data analysis. TM contributed to study design, interpretation of data and revision. All authors read and approved the final manuscript.

\section{Author details}

${ }^{1}$ Department of Trauma, Hand and Reconstructive Surgery, University of Rostock, Medical Center, Schillingallee 35, D-18057 Rostock, Germany. 2Department of Trauma, Orthopedic and Reconstructive Surgery, Klinikum München Harlaching, Sanatoriumsplatz 2, D-81545 Munich, Germany.

Received: 28 July 2015 Accepted: 7 November 2015

Published online: 14 November 2015

\section{References}

1. Pinzur MS, Sostak J. Surgical stabilization of nonplantigrade Charcot arthropathy of the midfoot. Am J Orthop (Belle Mead NJ). 2007;36:361-5.

2. Lowery NJ, Woods JB, Armstrong DG, Wukich DK. Surgical management of Charcot neuroarthropathy of the foot and ankle: a systematic review. Foot Ankle Int. 2012;33:113-21.

3. Robinson AH, Pasapula C, Brodsky JW. Surgical aspects of the diabetic foot. J Bone Joint Surg (Br). 2009;91:1-7.

4. Sohn MW, Stuck RM, Pinzur M, Lee TA, Budiman-Mak E. Lower-extremity amputation risk after charcotarthropathy and diabetic foot ulcer. Diabetes Care. 2010;33:98-100.

5. Peters EJ, Lavery LA, International Working Group on the Diabetic Foot. Effectiveness of the diabetic foot risk classification system of the International Working Group on the Diabetic Foot. Diabetes Care. 2001;24:1442-7.

6. International working group on the diabetic foot. http://documents.mx/ documents/pedis-1pdf.html. Accessed 15 June 2015.

7. Pakarinen TK, Laine HJ, Honkonen SE, Peltonen J, Oksala H, Lahtela J. Charcot arthropathy of the diabetic foot. Current concepts and review of 36 cases. Scand J Surg. 2002;91:195-201.

8. Pinzur M. Surgical versus accommodative treatment for Charcot arthropathy of the midfoot. Foot Ankle Int. 2004;25:545-9.

9. Mittlmeier T, Klaue K, Haar P, Beck M. Should one consider primary surgical reconstruction in Charcot arthropathy of the feet? Clin Orthop Relat Res. 2010;468:1002-11.

10. Alpert SW, Koval KJ, Zuckerman JD. Neuropathic arthropathy: review of current knowledge. J Am Acad Orthop Surg. 1996;4:100-8. 
11. Illgner $U$, Podella $M$, Rümmler $M$, Wühr J, Büsch $H G$, Wetz HH. Reconstructive surgery for Charcot foot. Long-term 5-year outcome. Orthopade. 2009;38:1180-6

12. Koller A, Hafkemeyer U, Fiedler R, Wetz HH. Reconstructive foot surgery in cases of diabetic-neuropathic osteoarthropathy. Orthopade. 2004;3:983-91.

13. Grant WP, Garcia-Lavin SE, Sabo RT, Tam HS, Jerlin E. A retrospective analysis of 50 consecutive Charcot diabetic salvage reconstructions. J Foot Ankle Surg. 2009;48:30-8.

14. Dalla Paola L, Brocco E, Ceccacci T, Ninkovic S, Sorgentone S, Marinescu MG. Limb salvage in Charcot foot and ankle osteomyelitis: combined use single stage/double stage of arthrodesis and external fixation. Foot Ankle Int. 2009;30:1065-70.

15. Pinzur MS. Neutral ring fixation for high-risk nonplantigrade Charcot midfoot deformity. Foot Ankle Int. 2007;28:961-6.

16. Farber DC, Juliano PJ, Cavanagh PR, Ulbrecht J, Caputo G. Single stage correction with external fixation of the ulcerated foot in individuals with Charcot neuroarthropathy. Foot Ankle Int. 2002:23:130-4.

17. Cooper PS. Application of external fixators for management of Charcot deformities of the foot and ankle. Foot Ankle Clin. 2002;7:207-54.

18. Alvarez R, Norris BL. Commentary: the use of external fixation for treatment of complex lower extremity neuropathic arthropathy. Curr Surg. 2005;62:623-4.

19. Sammarco VJ, Sammarco GJ, Walker Jr EW, Guiao RP. Midtarsal arthrodesis in the treatment of Charcot midfootarthropathy. J Bone Joint Surg Am. 2009;91:80-91.

20. Apelqvist J, Bakker $K$, van Houtum WH, Nabuurs-Franssen MH, Schaper NC. International consensus and practical guidelines on the management and the prevention of the diabetic foot. International Working Group on the Diabetic Foot. Diabetes Metab Res Rev. 2000;16 Suppl 1:S84-92.

21. Lamm BM, Gottlieb HD, Paley D. A two-stage percutaneous approach to Charcot diabetic foot reconstruction. J Foot Ankle Surg. 2010;49:517-22.

22. Grant WP, Garcia-Lavin S, Sabo R. Beaming the columns for Charcot diabetic foot reconstruction: a retrospective analysis. J Foot Ankle Surg. 2011;50:182-9.

23. Bevilacqua NJ, Rogers LC, Armstrong DG. Diabetic foot surgery: classifying patients to predict complications. Diabetes Metab Res Rev. 2008;24 Suppl 1:S81-3.

24. Chantelau E, Kimmerle R, Poll LW. Nonoperative treatment of neuroosteoarthropathy of the foot: do we need new criteria? Clin Podiatr Med Surg. 2007;24:483-503. ix.

25. Saltzman CL, Hagy ML, Zimmerman B, Estin M, Cooper R. How effective is intensive nonoperative initial treatment of patients with diabetes and Charcot arthropathy of the feet? Clin Orthop Relat Res. 2005;435:185-90.

26. Eschler A, Wussow A, Ulmar B, Mittlmeier T, Gradl G. Intramedullary medial column support with the Midfoot Fusion Bolt (MFB) is not sufficient for osseous healing of arthrodesis in neuroosteoarthropathic feet. Injury. 2014:45:38-43.

27. Baravarian B, Van Gils CC. Arthrodesis of the Charcot foot and ankle. ClinPodiatr Med Surg. 2004;21:271-89.

28. Garapati R, Weinfeld SB. Complex reconstruction of the diabetic foot and ankle. Am J Surg. 2004;187:81S-6.

29. Papa J, Myerson M, Girard P. Salvage, with arthrodesis, in intractable diabetic neuropathic arthropathy of the foot and ankle. J Bone Joint Surg Am. 1993;75:1056-66.

30. Wiewiorski M, Yasui T, Miska M, Frigg A, Valderrabano V. Solid bolt fixation of the medial column in charcotmidfootarthropathy. J Foot Ankle Surg. 2013:52:88-94.

31. Kaynak G, Birsel O, Güven MF, Oğüt T. An overview of the Charcot foot pathophysiology. Diabet Foot Ankle. 2013;4.

32. Marks RM, Parks BG, Schon LC. Midfoot fusion technique for neuroarthropathic feet: biomechanical analysis and rationale. Foot Ankle Int. 1998;19:507-10

\section{Submit your next manuscript to BioMed Central and take full advantage of:}

- Convenient online submission

- Thorough peer review

- No space constraints or color figure charges

- Immediate publication on acceptance

- Inclusion in PubMed, CAS, Scopus and Google Scholar

- Research which is freely available for redistribution 